verbindung zwischen Saug- und Heberflasche sorgt man dafür, daß zunächst in der ersteren keine Luftverdünnung, sondern eher ein schwacher Überdruck herrscht. Zur Filtration verwendet man $6 \mathrm{ccm}$, die man durch Zusammengießen zweier Röhrchen des Hauptversuches erzielt. Man bringt zunächst I,5 ccm mit der Pipette vorsichtig aufs Filter, läßt 5 Minuten darauf stehen und saugt durch Offnung der Heberflasche vorsichtig ab. Dann entfernt man das Glas mit dem ersten Filtrat, das unbrauchbar ist, weil es noch mit Kochsalzlösung stark verdünnt ist, stellt ein neues Glas hinein, sperrt den Abfluß und gibt 2,5 $\mathrm{ccm}$ aufs Filter. Nach 5 Minuten wird wieder abgesaugt, der Abfluß abgestellt, der Pfropfen der Saugflasche einen Augenblick lang gelüftet, der Rest des Serums aufgegossen und nach 5 Minuten wiederum abgesaugt. Die Lüftung des Pfropfens ist notwendig; da bei bloßer Abstellung des AusfluBrohres noch so viel Unterdruck herrscht, daB das Serumgemisch zu früh abläuft. Wir konnten bei unseren Filtrierversuchen eine Reihe interessanter Beobachtungen machen. Schon vorher habe ich erwähnt, daß die Zurückhaltung des Antigens direkt von der Kieselgurmenge abhängig ist. Würde es sich um einen einfachen FiltrationsprozeB handeln, so müßte man annehmen, $\mathrm{daB}$ es nur auf die Dicke der Filtrierschicht ankommt. Nach dieser Richtung hin wurden wir durch Versuche aufgeklärt, die wir mit größeren als den von uns sonst verwendeten Filtern anstellten. Erstere hatten 7,8, letztere 3,5 cm Durchmesser. Die filtrierende Kreisfläche ist demnach zirka fünfmal so groß. Wir brauchten also, um eine gleiche Schichtdicke zu erzielen, für die größeren Filter die fünffache Kieselgurmenge. Unsere Versuche ergaben aber, daß nicht nur bei dieser, sondern auch bei erheblich geringeren Mengen nicht nur das Antigen, sondern auch die gesamte Wassermann-Substanz adsorbiert wurde, und wir schließlich auf diejenigen Mengen zurückgehen mußten, die sich bei unseren Versuchen mit den kleinen Filtern als optimal erwiesen hatten. Man konnte somit von einer regulären quantitativen Beziehung zwischen Wassermann-Substanz und Kieselgur sprechen. Es hat sich ferner als zweckmäßig herausgestellt, mit dem Filtrat noch eine dritte Probe anzustellen, indem wir nämlich noch ein Röhrchen mit Zusatz von o,o5 ccm positivem Luesserum einsetzten. Wir stellten demnach 3 Proben an: Die erste mit, die zweite und dritte ohne Antigenzusatz; der dritten Probe wurde $0,05 \mathrm{ccm}$ Luesserum hinzugefügt. Bei unseren Filtrationen eines starkpositiven Hauptversuches fanden wir nun ganz regelmäBig und eindeutig folgende Formel: Im ersten Röhrchen ++++ , im zweiten - , im dritten -. In Anbetracht der großen Anzahl unserer Versuche und der ständigen Wiederkehr der genannten Formel glauben wir uns berechtigt, dieselbe als charakteristisches Kennzeichen des Luesserums und jede Abweichung von derselben als Beweis einer falsch gemachten Reaktion anzusprechen.

Im Gegensatz zu dem gesetzmäßigen Verhalten des wassermannpositiven Serums fanden wir beim normalen, besser wassermannnegativen Serum in der ersten und dritten Reihe ganz irreguläre Werte, während Reihe 2 auch hier negativ blieb. Ein sehr merkwürdiges Verhalten, das für das Verständnis des offenbar sehr verwickelten Vorganges von großer Wichtigkeit ist, zeigt die dritte Reihe. Während dieselbe beim wassermannpositiven Serum ausnahmslos negativ reagierte, fiel sie beim wassermannnegativen Serum in mindestens der Hälfte aller Fälle stark positiv aus, und zwar nicht nur in denjenigen Versuchen, in denen auch Reihe I positiv reagierte, sondern häufig auch beim negativen Ausfall dieser Reihe. Wir können uns das Phänomen zunächst nur folgendermaßen erklären. Beim Filtrieren eines positiven Hauptversuches bleibt das Antigen zurück. Die filtrierte Wassermann-Substanz bedarf eines erneuten Zusatzes von Antigen, um mit Komplement zusammen ein neues Wassermann-Aggregat zu geben. $\mathrm{Da} \beta$ es sich nicht um einfache Hemmung infolge von Antigenüberschuß handelt, kann aus dem durchweg negativen Ausfall der Reihe 3 geschlossen werden, welche, falls Antigen durchginge, mit frisch zugesetztem Luesserum sonst positiv reagieren müßte. Anders beim Normalserum. Hier bleibt nur die Erklärung, daß das nicht im
Wassermann-Aggregat verankerte Antigen durchs Filter geht, in Reihe I auf Zusatz neuen Antigens Hemmung infolge von Antigenüberschuß hervorruft, in Reihe 3 aber mit dem frisch zugesetzten Luesserum und Komplement ein typisches Wassermann-Aggregat bildet.

Wir können aus unseren Versuchen demnach folgendes schließen: $x$. Bei der Filtration eines Wassermann-Hauptversuches durch Kieselgur wird aus einem positiven Serum stets das Antigen zurückgehalten, aus einem negativen Serum in der Mehrzahl der Fälle nicht. Weswegen negative Sera nicht gleichmäßig reagieren, läßt sich zur Zeit noch nicht übersehen. 2. Ein Luesserum reagiert stets nach der Formel,,++++-- . Ein von dieser Formel abweichendes Ergebnis beweist nach unseren Erfahrungen einen Arbeitsfehler. (Aus dem Kaiser Wilhelm-Institut f. experim. Therapie, Berlin-Dahlem.)

\section{ENTHALTEN DIE ERYTHROCYTEN DES STRÖMENDEN BLUTES BEIM MENSCHEN TRAUBENZUCKER?}

\author{
Von \\ Martin Brant.
}

Die Frage, ob die menschlichen Erythrocyten für Traubenzucker durchgängig sind oder nicht, ist, wie auch aus dem Referat von GYöRGY (Neuere Anschauungen über den Blutzucker, Klin. Wochenschr. Nr. I 5) hervorgeht, durchaus noch nicht geklärt. Rona und MichaELIS, E. Frank, Bürger u. a. konnten sich von dem Glucosegehalt der roten Blutkörperchen überzeugen, während neuere Anschauungen von RICHTER-QuitTner, Brinkmann und vaN DaM u. a. die Impermeabilität der roten Blutkörperchen betonen.

Um diese Streitfragen zu klären, untersuchte ich auf Anregung von Prof. E. Frank Plasma, das ohne Zutun einer gerinnungshemmenden Substanz gewonnen wurde, und Vollblut mit der Moecki-Frankschen Makromethode auf Glucose, bestimmte durch sehr exakte Hämatokritenbestimmungen das Volumen der roten Blutkörperchen und berechnete aus diesen drei Faktoren den Zuckergehalt der Erythrocyten. Um eine Schädigung der roten Blutkörperchen durch irgendwelche Zusätze $\mathrm{zu}$ vermeiden und gleichzeitig die Gerinnung $\mathrm{zu}$ verhindern, wandte ich folgende Technik an:

Aus einer gestauten Vene im Strahl austretendes Blut wurde in gut paraffinierten, mit Blechkappe versehenen Spitzgläsern (Länge: to $\mathrm{cm}$, äuBerer Durchmesser: $1 \frac{1}{2} \mathrm{~cm}$, Glasdicke: $I, 5 \mathrm{~mm}$ ) aufgefangen und in einer bereitstehenden elektrischen Zentrifuge mit hoher Tourenzahl sofort zentrifugiert. Das so gewonnene, keine Spur von Gerinnung zeigende Plasma wurde mit einer paraffinierten Pipette in ein ebenfalls paraffiniertes Schälchen abgespritzt und genau $5 \mathrm{ccm}$ davon (nicht paraffinierte Pipette!) zur Makrobestimmung verwandt. Bei dieser Art der Versuchsanordinung fand ich in I2 Fällen die roten Blutkörperchen unter physiologischen Bedingungen, sowie bei pathologisch erhöhtem oder erniedrigtem Plasmazuckerspiegel stark glucosehaltig.

Da Creveid und Brinkmann, Csaki u. a. mit der Mikromethode gearbeitet hatten und zu gerade entgegengesetzten Resultaten gekommen waren, prüfte ich meine Ergebnisse auch mit der Basgschen Methode nach.

Die Technik war hierbei dieselbe wie oben, nur wurde das abgeheberte Plasma sofort mit einer paraffinierten Pipette auf die Plättchen getropft und sofort gewogen.

Auch mit der Bangschen Mikromethode konnte ich in ro Fällen die mit der MoEckL-Frankschen Makromethode erhaltenen Resultate nur bestätigen. Die roten Blutkörperchen enthielten immer erhebliche Mengen Traubenzucker, und zwar öfter gleich viel, meistens etwas weniger als das Plasma, was folgende Tabelle zeigt. 


\begin{tabular}{|c|c|c|c|c|}
\hline & $\begin{array}{c}\text { Glucosegehalt des nativen } \\
\text { Plasmas }\end{array}$ & $\begin{array}{l}\text { Glucosegehalt des } \\
\text { Vollbluts }\end{array}$ & $\begin{array}{l}\text { Volumen der } \\
\text { Erythrocyten }\end{array}$ & $\begin{array}{c}\text { Glucose- } \\
\text { gehalt der } \\
\text { roten Blutk. } \\
\text { (berechnet) }\end{array}$ \\
\hline I & O, I3 \% M. F. M. $\left.{ }^{1}\right)$ & $0,13 \% \quad$ M. F. M. & 36 & $0,13 \%$ \\
\hline 2 & 0,06 \% M. F. M. & $0,06 \% \quad$ M. F. M. & 43 & $0,06 \%$ \\
\hline 3 & 0,075\% M. F. M. & $0,070 \%$ M. F. M. & 35 & $0,062 \%$ \\
\hline 4 & $0,104 \%$ M. F. M. & $0,095 \%$ M. F. M. & 40 & $0,082 \%$ \\
\hline & $\mathrm{O}, \mathrm{IO}_{3} \%$ B. M. M. $\left.{ }^{2}\right)$ & 0,091 \% B. M. M. & 40 & $0,075 \%$ \\
\hline
\end{tabular}

Es wurden auch an demselben Patienten einzeitig sowohl mit der Makro- als mit der Mikromethode im Plasma (ohne
Zusatz) und im Vollblut Zuckerbestimmungen gemacht. Die Vergleichsresultate differierten nur um wenige Milligramme und bewiesen immer wieder den Zuckergehalt der roten Blutkörperchen (s. oben Tabelle Nr. 4).

Da bei dieser Versuchsanordnung jede Gerinnung verhütet, die roten Blutkörperchen durch keine Agentien geschädigt wurden, glaube ich mit Sicherheit sagen zu dürfen, daß die roten Blutkörperchen des Menschen zuckerhaltig sind. Eine ausführliche Besprechung der Versuchsresultate erfolgt an anderer Stelle. Aus der medizinischen Universitätsllinik zu Breslau. (Direktor: Geh. Med.-Rat Prof.Dr. Minkowski.)

\section{KASUISTISCHE MITTEILUNG.}

\section{EIN FALL VON OPERATIV BEHOBENER VOLLKOMMENER TAUBHEIT INFOLGE GEHÖRKNÖCHELCHEN-FIXATION. \\ Von}

\author{
Dr. Theodor v. Liebermann. \\ Otologen des Spitals.
}

Der in der.Sitzung vom 4. März 1922 des Kgl. Ärztevereines in Budapest vorgestellte Patient K. B., 22 Jahre alt, Barbier, gab im Dezember v. J. an, seit er sich erinnern könne, also von frühester Kindheit an, auf dem rechten Ohre taub gewesen zu sein. Das linke Ohr ist seit geraumer Zeit ebenfalls krank, jedoch hört er damit leidlich. Sonst in der Anamnese nichts von Belang. Lues negiert.

Befund: Rechts vollkommen unbeweglicher Hammergriff bei normalem Trommelfell, welches aber stark eingezogen erscheint; links geringer eiternder Proze $\beta$ im Mittelohr. Gehör rechts mit allen Prüfungsmethoden untersucht null, links $6 \mathrm{~m}$ Flüstersprache. Rechts keine Knochenleitung, Weber nach links. Keine Labyrinthausfallserscheinungen. Tuben frei.

Am 12. Dezember nach Rücksprache mit dem Patienten, der schon viele Ohrenärzte befragt hatte und stets als unheilbar taub abgewiesen worden war, Operation. Hammerentfernung, die nach Umschneidung des Hammergriffes und Tenotomie mit einem sog. Storchschnabel vorgenommen wird, wobei es sich zeigt, da B das untere Ende des Hammergriffes vollkommen fest an das Promotorium angewachsen war und bei der Hammerentfernung abbrach.

Sofort nach der Operation hört Pat. Flüstersprache auf $2 \mathrm{~m}$ Entfernung, hört die aufgesetzte Stimmgabel, die GaItonsche Pfeife, bloß die tiefsten Töne (A 48) werden nicht gehört. Der Zustand ändert sich im Laufe der Heilung, die ohne Störung, jedoch mit Zurückbleiben einer trockenen Trommelfellperforation vor sich geht, nicht und ist zur Zeit (März 1922) noch genan derselbe.

Der Fall ist meiner Ansicht nach von zweifacher Bedeutung: erstens von sinnesphysiologischer und zweitens von praktischer.

Die allgemein herrschende Ansicht ist bis jetzt die, da.B bei intaktem inneren Ohre keine absolute Taubheit bestehen könne. Der Fall beweist aber, sofern wir nicht den Vorwand gebrauchen, daß es sich um eine funktionelle Störung gehandelt hat, das Gegenteil. Dieser Annahme widerspricht aber meiner Ansicht nach hinlänglich der Umstand, daß das Leiden seit frühester Kindheit und bloß auf dem einen Ohre bestanden hat, ferner, daß Pat. sich na.ch vielen, ihn abweisenden Årztemeinungen zu einem Eingriff entschloß, der ihm als nicht ganz ungefährlich bezeichnet worden war.

Eine Erklärung für die bei intaktem inneren Ohre bestehende Taubheit können wir also nur darin finden, daß die Sinneszellen von keinem adäquaten Reiz haben getroffen werden können. PANSE $^{1}$ ) berichtet darüber, daß bei völlig starren Fenstermembranen Taubheit bestehe; es war aber bisher nie einwandfrei festzustellen, ob bei starren Fenstern, die ja meistens infolge Otosklerose erstarrt sind, nicht auch die Nervenendigungen degeneriert waren. Meist fanden sich in den Präparaten Zeichen der Zerstörung des Sinneszellenapparates. $\mathrm{BR}_{\mathrm{U} H \mathrm{HL}^{2}}$ ) zeigte aber, daß diese Zerstörungsmerkmale größtenteils wohl postmortale Vorgänge darstellen, denn schon wenige Stunden nach erfolgtem Tode fixierte Präparate normaler Ohren weisen solche auf.

Der adäquate Reiz der Gehörhärchenzellen ist im Sinne SHAMBAUGHs ${ }^{3}$ ) einzig die Wellenbewegung der Endolymphe, die durch Schwingungen, welche entweder die Gehörlknöchelchen (Trommelfell) oder die Knochenkapsel treffen, in der Endolymphe erzeugt werden. Jede andere Schwingung, mag sie die Knochenkapsel treffen, die keine Wellenbewegung in der Endolymphe hervor-

1) M. F. M. - MOECKL-FRANK sche Makromethode.

2) B. M. M. - BANG sche Mikromethode. zurufen imstande ist, stellt keinen adäquaten Reiz der Sinneszellen

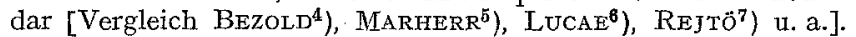

Nun haben aber die Untersuchungen von $\mathrm{TRÖLTSCH}^{8}$ ) bewiesen, da $\beta$ die Bewegungen der beiden Fenster infolge der praktischen Unzusammendrückbarkeit der Endolymphe in engster Verbindung zueinander stehen. Die physikalischen Untersuchungen REJTös ${ }^{7}$ ) an seinem Modell haben die Einzelheiten und praktischen Resultate dieser Zusammenhänge noch besser ins rechte Licht gerückt.

Wir müssen also für den vorliegenden Fall die Erklärung annehmen, daß ein in der Kindheit abgelaufener entzündlicher Proze $B$ einesteils das runde Fenster verdickt und auf diese Weise eines Teils seiner Elastizität beraubt hat, anderenteils durch schrumpfende Adhäsionen den Hammergriff in einer, dem Promotorium ad maximum genäherten Stellung festgestellt hat, wobei die Fußplatte des Steigbügels stark eingedrückt, vielleicht verklemmt, ebenfalls vollkommen versteift wurde. Das wenig elastische runde Fenster mag durch diese Eindrückung des ovalen Fensters noch unter Druckverhältnisse geraten sein, die eine Schwingung desselben vollkommen unmöglich gemacht haben. Die zwischen ganz starre Wandungen geratene Endolymphe konnte keine Wellenbewegungen ausführen, die sie treffenden Schwingungen also nicht in den Sinneszellen adäquate Reize umsetzen. Die Entfernung des fixierten Hammers löste diese Hindernisse.

Es wäre noch denkbar, daß die hervorgerufenen Drucksteigerungen in der Endolymphe die Ursache der Taubheit gewesen wäre, wie wir sie nach BIEHL $^{2}$ ) bei vorübergehenden Störungen annehmen und mittels Schwitzkuren zu bekämpfen suchen. Gegen diese Annahme spricht aber ein sehr gebieterisches Wort, die viele Jahre lange Dauer der Taubheit. Denn es ist eine Erfahrungssache, daB Drucksteigerungen im Ohre, die zu Taubheit führen, sofern sie nicht innerhalb einer verhältnismäßig Ixurzen Zeit (Tage, höchstens wenige Wochen) ausgeglichen werden können, zu dauernder schwerer Gehörstörung führen, worin wir wohl eine Analogie mit dem Glaukom des Auges erblicken können, bei dem ja bekanntlich ein länger anhaltender Anfall schon irreparable Veränderungen im Sinnesapparat verursacht und zu dauernder Blindheit führt. Das gute Resultat des nach vielen Jahren vorgenommenen Eingriffes schließt daher wohl diese Annahme aus.

Der Fall mag also vielleicht als Experimentum crucis für die Shambaugri-TröLtsch-Rejtösche Theorie gelten und wäre einer gelegentlichen Nachprüfung wert. Selbstverständlich wären nur gelungene Heilungen maßgebend, da es ja gleichzeitig auch entzündliche Adhäsionen gleicher Stärke am Steigbügel selbst geben kann, die durch die Hammerentfernung nicht gelockert werden können.

Die otologisch-praktische Würdigung des Falles gestaltet sich meiner Meinung nach folgendermaßen: Den Eingriff der Hammerentfernung dachte sich angeblich zuerst der Anerikaner JAck Mitte des vorigen Jahrhundertes aus, jedoch wurde derselbe so von JACK, wie von allen, die nach ihm denselben übten, stets in Fällen angewandt, in denen die Prüfungen des Ohres ein gutes Funktionieren der Knochenleitung ergaben, somit die Hörstörung allein auf ein Hindernis in der normalen Schalleitung durch die Gehörknöchelchenkette bezogen warde. Der Eingriff wurde infolgedessen fast stets bei sicherer Otosklerose ausgeführt, war stets erfolglos, meist auch gefährlich, da ja die Otosklerose, wenn sie die Kette schon so schwer angegriffen hat, daß eine Versteifung derselben stattgefunden hat, meist schon viel früher das Lig. anullare verknöchert, ja meist auch das innere Ohr verändert hat. In solchen Fällen muß der Eingriff daher erfolglos sein, da wir ja wissen, daß die Knochenleitung resp. das direkte tympanale Hören auch ohne Trommelfell und Kette für die meisten Tonlagen ausreicht, anderenteils gefährlich, weil aus der Hammerentfernung, die oft auch mit Amboßentfernung vereint ausgefühtt wurde, leicht ein gewaltsames Herausreißen des Steigbügels aus dem Fenster entstand. 